\title{
رمزية الرنك على المعدن (نماذج منتخبة )
}

أ.م .د محمد خضر / جامعة الموصل/ كلية الاثار

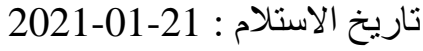

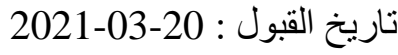

الملخص

يهذف البحث الى بيان رمزية الرنك على المعدن حيث شهد هذا العنصر انتشاراّ ملحوظاّ على التحف المعدنية ليكون دليل تميز للسلطان والأمير الأيوبي والمملوكي . فنفذ بشكل مباشر على التحف المعدنية المتنوعة المباخر والأواني والأباريق)وغيرها من التحف الاخرى ــ ويعد البحث عن الرنلك احد العناصر

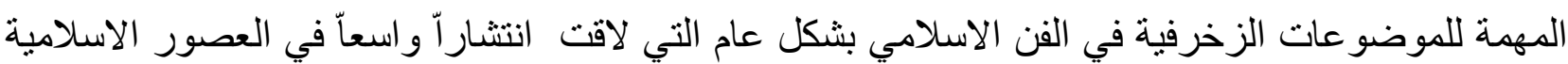
و استخدمها كونها تؤثر بشكل رمزي وفكري على تفكير الأمراء والسلاطين وهو الثي الذي يتسابق الى لى لئ تغييره وفرضة اثناء تغيير الحكم. وقد بينا في هذا البحث عن الرمزية ودلالاتها والمعادن والتعدين قديما وفي العصور الاسلامية وأهم الرنوك التي نفذت عليها كرنك الكاس الذي يعد اشهرها ويطلق على ساقي البلاط ورنك الدواة للثخص الذي يكتب اوامر السلطان ويعرض عليه البريد الوارد من الخارج يليه رنك البقة المختص بلباس السلطان ورنك البولو اثارة الى الثخص الماسك لعصا اللعب ثم رنك النسر شعار صلاح الدين وبعض المماليك دالةً على السيطرة و القوة واخيراً الرنك الكتابي الذي دونت به أسماء الملوك و الو لاة الى جانب العبار ات الدعائية. الكلمات المفتاحية هي : رمزية , رنك , معدن ,مملوك ,سلطان 


\title{
Symbolism of Heraldry on Metal (Selected Samples)
}

Receipt date: 2021-01-21

Date of acceptance: 2021-03-20

\begin{abstract}
:
This research aims to show the symbolism of the heraldry on the metal, as this element has witnessed a remarkable spread on metal artifacts to be a distinctive sign of the Sultan, Ayyubid and Mamluk prince. So it was implemented directly on the various metal artifacts, incense burners, pots, jugs and other Islamic artifacts in general. It was widely spread in the Islamic era and used as it symbolically and intellectually affects the thinking of princes and sultans, which is something that is heading to change and imposed during the change of government. We have shown in this research about symbolism and its connotations of state heraldry, minerals and mining in ancient times and in Islamic times. The most important symbol on which it was carried out the sultan juice cup, which is the most famous of which is called the court cup holder. Secondly, comes the heraldry of the scribe, the person who writes the Sultan's orders and displays the mail coming from outside, followed by the sack heraldry that is concerned with the Sultan's dress and the polo heraldry is a sign for the person holding the playing stick, then the eagle heraldry the slogan of Saladin and some of the Mamluks, indicating control and power, and finally the written heraldry in which the names of kings and rulers were recorded, along with propaganda phrases.
\end{abstract}

Key words: Symbolism, Heraldry, Metal , Mamluk, Sultan 
المقدمة:

حظيت الفنون التطبيقية باهتمام الملوك والسلاطين والامراء والمماليك، حتى اصبحت الرنوك نتاجات مهمة تشير الى وظائفهم في الدولة. فرسمت ونقشت وختمت على خامات عديدة، ومنها المعادن. لتصبح بعدها من العلامات التجارية للمنتجات الصناعية التي تباع للناس.

لذلك نجد شيوعاً في استخدام الرنوك في القرون الوسطى بثكل كبير ، لتدل على رمزيات ابتغيت في النفوس ، وهو على جانب من الاهمية؛ كونها علماً بارزاً كثيراً ما يعزز من فهم الدراسات التاريخية، والقت الأضواء على نواحِ فنية واثرية على التحف والمعادن فان اهمية البحث تأتي في تحليل ووصف هذه الرنوك واشكالها واستخدامها للدلالة الوظيفية للشخص الذي يخدم البلاط الخلافي والسلطاني وهي تهدف الى اظهار ما تميزت به صناعة التحف المعدنية في العصر الايوبي والمملوكي وتأثيرها بشكل مباشر على الثروة الفنية الزخرفية في العصور اللاحقة وابراز مدى ازدهار الفنون واهتمام الملوك والسلاطين بها اضافة الى ذلك ادت التحف المعدنية في حياة اجدادنا دورا عظيما بالرغم من قلة ما وصل الينا من العصور السابقة ، ونظرا لذلك طوًر الفنان المسلم عبر العصور المتعاقبة التعبير عن الذات بشكل رسوم وفنون جمالية تتفق مع مبادئ الدين الاسلامي ، فاشتمل البحث على الرمزية وماذا تعني ثم الرنك لغة واصطلاحا وأهم انواع الرنوك التي تتوعت بين البسيط المتكون من رنك واحد والمركًب والمكًون من اكثر من رنك او ركنين مجتمعين أو رنك وظيفي دلالة على الوظيفة التي يشتغل بها صاحب الرنك واخيراً وهو الكتابي الذي يضم نصا كتابيا فيه اسم الامير أو السلطان. هذا ومن الجدير بالاهتمام ان اغلب الرنوك الواردة بالبحث تعود الى

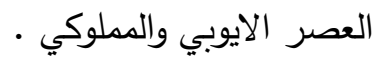

1

جاءت من فعل رمز ، ورمَز الثخص أومأ او أشار بالثفتين والعينين بدون الصوت بقصد التفاهم اما رمَز الثيء دل بها عليه مثله بصورتها او نموذجها ، والرمزية اسم مؤنث منسوب الى الرمز والرمز يعني الاشارة والايماءة (ابن منظور، د.ت، ص215)، والاصوات التي ينطق بها رموز دالة على الالفاظ (تودوروف، 2012، ص20)، تعني لنا الرمزية لدلالة عن شيء 
معروف لا يرى بالعين المجردة (سيرنج، 1992، ص38)، وعلاقة الرمز بالفنون منذ الرسوم الاولى على جدران الكهوف كركيزة مهمة للأبداع ومنها يستقي الفنان عالمه الخاص واثكال عناصره الفنية والذي يتكون من شكل وصورة ورنك وخطوط ولون هندسي او طبيعي حتى اوجد قاموسه الذي يعتمد عليه بالعديد من الرموز لاسيما الهندية والكتابية التي استتبطت منها الفنون الزخرفية لتصاميمها واشكالها الرئيسة (النقطة والخط والدائرة والمثلث )ومنحتها امكانية الوصول على تصاميم مختلفة ومتتوعة وذلك بتكرارها او مزاوجتها وهو ما وجدناه في تزيين الفنان المسلم للرنوك على التحف المعدنية . 2. الرنك لغة واصطلاحاً:

الرنك لفظ فارسي معناه في اللغة العربية شعار أو لون (غالب، 1988، ص206). وهو عبارة عن رسم او خط كتابي او شكل حيوان، كطير او رسم لأداة معينة او قد يكون شكلا هندسيا، يتألف من لون واحد أو الوان عديدة(حسان وعباس، 1999،ص103)،، فتعد الرنوك امتيازا خاصا للأمراء والعسكرين حيث كان هناك أنظمة وقواعد لا حصر لها والظروف التي يمنح لها (مصيلحي، 1983، ص1271).

عرفت الرنوك منذ أقدم العصور، إلا أن مدلولاتها اختلفت في العصور الوسطى، إذ ارتبطت كثيراً بالجوانب الدينية، واتخذت شعاراً للعديد من الامم السابقة. فاستخدمت القبائل رايات ذات أشكال معينة حملت صور معبوداتهم، كما عرف الغرب الرنوك، فاستخدموها على نطاق فردي وعائلي بثكل واسع ونتيجة لذلك اتُخذت لها سجلات رسمية خاصة تضم اشكالها والوانها ورسومها مع القاب الاسر والعائلات المختصة بها ، يتوارثونها جيلا بعد جيل وكان ذلك نتيجة أتصال هؤلاء الاوربيين بالعرب في بلاد الثام أيام الحروب الصليبية واقتباسهم اياها منهم وقاموا بتقليد بعض الرنوك التي كانت تستخدم في البلاد الشرقية والاسلامية فاتخذ رمز (النسر المزدوج )الذي صار شعر للعديد من الامبراطوريات الالمانية والنمساوية والمجرية والروسية ونجده شعار عربي موغل في القدم فاستخدم من قبل السومرين والحثين وبعدها ليكون شعارا لسلاطين السلاجقة (زيغريد، د.ت)(كرستي، د.ت). كما عرف الحثيون الرنوك والاغريق والرومان وغيرها من الثعوب، حتى أنها اتخذت في عصر النبوة بهيأة الوية ورايات. فالبياض كان لوناً للرسول (صلى الله عليه وسلم ) يوم فتح مكة (عبدالرزاق، 2001، ص25) فيما لعب اللون دوراً اساسياً في تمييز بين المتثابهة منها من حيث الثكل والرمز، وفي الحديث على الرنوك نجده يثبت على جميع الاشياء المنسوبة الى صاحبه، فزينت مطابخ السكر واكياس تعبأتها والاملاك والمراكب وغيرها كما ينقش على قماش خيوله 
وعلى السيوف والاقواس والادوات الخثبية والمعدني (مهدي، 2008، ص35)،وحتى انه وصلت درجة اعجاب الناس بالسلاطين ورنكه الثخصي لاسيما المماليك والسلاطين ذوي الاعمال الحسنة.

يتألف الرنك من نطاق واحد أو أنطقه عديدة. ومما يجدر ذكره ان الوان الرنوك على التحف المعدنية نادرة جداً، اذ نجد لا تتعدى اللونين في أغلب الاحيان، واهمها اللون الابيض (الفضي ) والاحمر (الذهبي ).(خضر، 2001، ص156)، فكانت الرنوك في بداياتها تتقش أو ترسم على التحف المعدنية وغيرها من دون أنطقه تحيط بها ثم تطورت بعد ذلك لتزين بأشكال دائرية او مربعة على الاغلب، بغية فصلها عما جاورها، فضلاً عن إعطاء استقلالية للرنك عن الزخارف الاخرى (عبدالعظيم، 2009، ص409).

$$
\text { ومن أهم انواع الرنوك هي: }
$$

1. الرنوك البسيطة: وهي الرنوك التي تتضمن شعاراّ واحداّ .

2. الرنوك المركبة: وتثتمل على اكثر من رمز او شعار واحد.

3. الرنوك الكتابية: وهي رنوك لا تحمل علامات، بل نصوص كتابية باسم السلطان أو المملوك (مصطفى، 1944،

الرنوك الوظيفية: يقصد بها علامات دالة على وظائف كان يشغلها بعض الامراء والمماليك والسلاطين.

ان حاجة الانسان للمعدن سواء في السلم او الحرب ضرورية فالأدوات المنزلية من اواني طبخ أو شرب وادوات حربية كالرماح والسيوف وما يستخدم منها للزراعة كالفأس والمعول تحتاج الى المعدن واستخراجها (العمري، 2012، ص77)، ولذلك ترتبط حياة الانسان على سطح الارض ارتباطا وثيقا بالمعادن. فجاء استخدام الإنسان للمعدن محظ صدفة جاءت بعد معرفته للنار ، ثم تطور بعد ذلك وتعامل معه ليصنع اشياء عديدة كان يستخدمها في حياته اليومية. 
عرف الأشوريون ( 2000 - 626 ق م ) والبابليون ( 2006- 1595 ق م ) والأكديون ( 2200-2900 ق م ) صناعة التعدين (الجادر، 1985، ص241) (المعماري، 2018، ص394-397)، واستخدموها بشكل واسع؛ نظراً لاتصالهم مع الثعوب المجاورة، واهتم كثيرا الرومان بصناعة التعدين حيث كان تركيزهم على الاستيلاء على المناجم الاساسية لأستخراج الحديد والنحاس (Brown, 1989, P.2)، في حين نجد العهود التي سبقت ظهور الأسلام اشتهرت الجزيرة العربية بصناعة المعادن لاسيما صناعة السيوف فكانت السيوف اليمنية تصدر الى البلدان المجاورة لها مستخدمين الرصاص والحديد في عمل الكثير من الحاجات المعدنية التي كان من اهمها السيوف والرماح والدروع (جواد، 1997، ص1517) ومما لاشك فيه استمرارية هذه الصناعات بعد ظهور الدين الاسلامي ان الصناعات المعدنية ظلت نشطة وعلى ما كانت عليه بعد الفتح الإسلامي للأقاليم، لقد كانت بداية شيوع استخدام المعادن في العراق على شكل ادوات حربية لرؤوس حراب، فكان استخدامه بدون طرق وبشكل طبيعي. ومن وسط شبه الجزيرة العربية جلب تجار من البحرين لحساب السومرين والاكديين (الجادر، 1985، ص241-243) وفي العصر الاسلامي اهتم المسلمون بكل المعادن، حتى ان ذكرها قد ورد في القران، كما في قوله تعالى: (وَأَنَزَلْنا الْحَدِيدَ فِيِهِ بَأْسُ شَدِيدٌ وَمَنَافِعُ لِلنَّاسِ (سورة الحديد، آية 25) .(واشتغل به النبي داؤود (عليه السلام)، إذ أخبرنا جل في علاه ذلك في

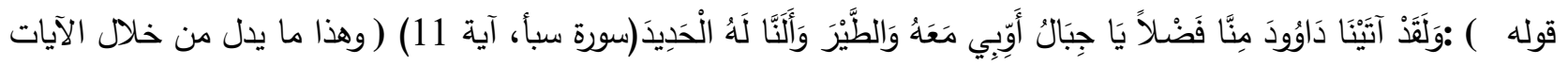
القرآنية وعلى وجود الحديد والى فائدته ومعرفة سكان شبه الجزيرة بالمعادن والتعدين وهم على دراية تامة بصهر المعادن وصناعتها .

وامتازت التحف المعدنية في فجر الاسلام بنسبة قليلة يعود السبب في ذلك الى اعادة تشكيلها عبر العصور اللاحقة فمن الصعوبة أن نجد سلسلة كاملة نستطيع ان نحدد العصور المتتالية للتحف المعدنية (مرزوق، 1965، ص133). ونلاحظ وجود ثغرة واسعة في تضأل الاواني المعدنية في بداية العصر الاسلامي هناك من يعزو السبب الى الاختلاف العقائدي في الدين الاسلامي وديانات وعقائد الامم الاخرى ودفن المقتتيات المعدنية التي كانت تستخدم في الحياة اليومية وذلك لإيمانهم بحياة ما بعد الموت (حميد، 1985، ص277) ، وقبل الدخول بأنواع الرنوك وتمثيلها على انواع المعادن لابد لنا من التعرف وبشكل مقتضب عن طرق صناعة المعادن واساليب زخرفتها فمن اقدم الاساليب وابسطها هي الطرق وتتم بمراحل عدة تبدأ بقطع صفائح معدنية حسب الرغبة ثم توضع في قالب خثبي وثم تحفر الزخارف بشكل بارز على المعدن ويقوم بعد ذلك بعملية الطرق 
والضغط ولزخرفة المعادن طرق عديدة اهمها ما يلي : (الطرق ) وتتم بوضع صحائف معدنية بحسب الثكل المراد تنفيذه وتحفر بعد ذلك الزخارف المنوعة عليه بواسطة الطرق والدق مع الضغط القوي وتحدد بعض تفاصيل الزخرفة بواسطة الحز وتُملا بمادة النيلو لتوضيح تفاصيل مهمة مثل الأشكال الأدمية والحيوانية والنباتية والرنوك المنفذة عليها كذلك ، وتليها طريقة اخرى وهي (الحفر ) بعد تعيين الصفيحة المراد زخرفتها وفق الثكل المطلوب ثم تتم عملية الزخرفة بإزميل من الحديد لكي تبرز الزخرفة عن خلفية الثكل المطلوب ، والطريقة الاخرى هي (التكفيت ) وتتفذ بعد العمليات السابقة وازالة جزء من الزخارف مع ابقاء الجزء الوسطي من الثكل بارتفاعه الاصلي تنزل اسلاك رقيقة مطروقة من معدن غالي الثمن مثل الفضة وتضغط حافاتها بواسطة ألة حادة حتى تمتد وفق الثكل المراد اضافة الفضة او المعدن الثمين الى الجزء المزخرف. (الجمعة، 1975، ص37-39) (صوى، 2005، ص125، 127، 129، 152) وتحدد الزخارف بطريقة الحز بألة حادة لتظهر لنا الزخارف بشكلها النهائي(العبيدي، د.ت، ص 121). فيما اذا كان المعدن صلبا فيستخدم في تتفيذ الزخارف طريقة مغايره للأولى وبواسطة الحفر . 5. اهم الرنوك التي حملتها التحف المعدنية: الكأس:

وهو رنك يطلق ويسمى به الساقي الذي يتولى مد السماط وتقطيع اللحم وسقي المشروب بعد رفع السماط. وقد وضع هذا الرنك على الغالب للثخص الذي يقوم بعملية ادارة المشروب وكل السوائل في البلاط الملكي او الخلافي (القلقشندي، 1915، ص454)، ويرجع كثرة هذا الرنك الى كثرة عدد السقاة واقبال الامراء عليها لأنها من الوظائف التي تؤهل شاغلها الى السلطنة (داود، د.ت، ص336)، ولذلك نجد ان هذا الرنك الاكثر شيوعا على التحف في العصور الاسلامية لاسيما في العصر المملوكي نظرا لكثرة الثخوص المشتغلين بهذه الوظيفة (حسن، 1981، ص326) .

وقد امدتا الاثار والتحف بأثكال متتوعة لرنك الكأس فجاء مفردا احيانا بلا منطقة تحيط به أو داخل منطقة مستديرة يملا فيها الكاس الاطار الذي يحتويه كما يأتي مع غيره فيشكل المنطقة الوسطى أو السفلى ، ومن المعادن التي حملت هذا الرنك قطعة محفوظة في متحف الفن الاسلامي بالقاهرة تعود الى القرن 8هـ / 14 م تستخدم لغسل وتنظيف الايدي(شبكة الانترنيت ( www.musemwuf.org (لوح 1 ) ، موزعا بشكل مرتب على الحافة العليا للآناء محاطا بدائرة تبلغ حوالي ستة دوائر في 
مركزها الرنك هذا بالإضافة الى تزيين البدن الرئيسي لنفس الرنك ولكن محاطا بدوائر اكبر من سابقتها ، وصندوق صغير من النحاس المكفت بالفضة عليه كتابات لاحد الامراء المماليك وهو محفوظ بمتحف الفن الاسلامي (لوح 2) ، فضم على رقبة الصندوق رسوم حيوانات على خلفية لرسوم اغصان التوائية في وسطها دائرة تضم رنك الكاس وكتب على الغطاء نص دعائي يذكر فيها اسم الامير المملوكي طغاي احد (أحد) امراء السلطان الناصر محمد ( 639-741 هـ /1293-1341م )، اسمه طغاي تمر الساقي وهو سيف الدين الناصري الساقي احد الامراء المقربين للسلطان الناصر محمد زوجه ابنته نظرا لما يمتاز من القبول والقرب من السلطان الانف الذكر الذي كان ذو ولاء مطلق له حتى توفي سنة 733 هـ ـ. (الصفدي،1998، ص603) (حسن، 1956، ص169) ومن خلال ملاحظة انواع الكؤوس التي مثلت على التحف المعدنية نجد هناك اختلاف في كل رمز كاس وكما هو ممثل في (الثكل رقم 1 ) . كما وزين رنك الكاس على شمعدان كتبغا، وهو مغولي الاصل دخل الحياة المملوكية لعد هزيمة المغول في موقعة عين جالوت سنة 658 هـ / 1260 م وقدومه الى مصر مع اسرى المغول ، والذي تولى السلطة فيما بين سنتي (696/649 هـ -1296/1294 م) ، والذي عدًه بعض الباحثين اول رنك حقيقي يشتمل على رمز وظيفي وفيه شعار الكاس للساقي ، الا ان النقوش الكتابية لا تثير الى صاحبة السلطان لكن صنع الثمعدان لكتبغا في اثثاء فترة خدمته للسلطان ، اخذت الكتابة المنفذة عليه أشكالا أدمية في تكوينها وهندتها بشكل مميز مصورة محاربين يرتدون السيوف والدروع (www.islamicart.museumwnt.org) ثلاث اجزاء تفصله ثلاث دوائر تشتمل هذه الدوائر المفصصة على دائرة ثانية تتضمن الكاس في الجزء السفلي (لوح 3) (اردنا ذكر هذه التحفة على الرغم اننا ومن خلال اطلاعنا على الصور لم نجد الرنك بشكل واضح ، فعلى الاغلب تمت ازالة بعض من الزخارف المنفذة عليه في وقت لاحق)، كما وحملت صينية محفوظة في مقتتيات خان مرجان قطرها( 80 سم ) زينت هذه الصينية اربع دوائر يتوسطها رنك الساقي، (حسن، 1970، ص465) تحيط بها كتابات نسخية مكفته بالفضة دونت القاب مملوكية محاطة برسوم نباتية من الرقش العربي (الارابيسك ) دليل متحف الاثار العربية في خان مرجان ، ص 36)، (لوح 4 ) ، وضم هذا الرنك مطارق الابواب فزين باب مدرسة (طنطاوي، 2005، ص252)( لوحة رقم 43-أ ص259) ألأ أنَّه يثترك معاه رنك أخر (لوح 5 ) م 
الدواة هي من الادوات التي صنعت لحفظ الاقلام والاحبار اطلق عليها العديد من التسميات كالمقلمة والمحبرة والدواة وتصنع من النحاس او البرونز المكفتة زخارفه من الذهب والفضة ، وتتألف الدواة من اربعة عناصر رئيسة تتمثل في جزأين مستطيلين او ثلاثة تثير الى موضع القلم المصنوع من القصب وصندوق صغير يمثل المرملة او المتربة ودائرتين صغيرتين تمثلان موضع الحبر والنشاء واخبرا فراغ نصف دائري خصص لوضع الممسحة وهي قطعة قماش كانت تخصص لتنظيف الاقلام. (يوسف، 2010، ص326) (القلقندي، 1915، ص431) هو شعار الدودار والمؤلف من مقطعين (دواة ) وتعني ما يكتب منه ، والثاني (دار ) وتعني ممسك الدواة وكانت معروفة عند العباسيين حتى وصلت الى المماليك عن طريق السلاجقة تحت اسم (الدوتدار) ،(الباشا، 1966، ص519) ويختص صاحبها بتبليخ الرسائل الى السلطان وتبليغ اوامر السلطان (احمد، 1974، ص102)، ويتولى امرها وما ينضم ذلك من الامور اللازمة (دهمان، 1990، ص77)، والدودارية وظيفة تضم كذلك عرض القصص والبريد واخذ الخط السلطاني فكانت الدواة عند السلاجقة من علامات الوزارة وتعطى الى الوزير يوم تتصيبه دواة من ذهب دليل على مدى رفع مكانة صاحب الدواة وما يحمله من مسؤولية كبيرة لدى السلطان آنذاك(دهمان، 1990، ص78).

مراجعة الكتابات والزخارف ، ويتمثل رنك الدواة على عناصر رئيسة جزأين مستطيلين او ثلاثة تثير الى موضع اقلام القصب المستخدمة في الكتابة وصندوق صغير يمثل المرملة او المتربة ودائرتين صغيرتين يوضع فيها الحبر وأخيراً فراغ على شكل نصف دائرة خصص لوضع الممسحة وهي قطعة قماش تستعمل لتنظيف الاقلام (احمد يوسف، 1976، ص98) (عدره، رشا، (109)، 2013

ومن اهم النماذج التي استطعنا الحصول عليها هو طست من النحاس الاصفر المحفوظ في متحف الفن الاسلامي وهو للأمير قطلوبغا والذي يؤرخ في سنة (778 هـ/1376م ) ، (وبأسم الجناب العالي المولوي الاميري الكبيري...... سيف الدين قطلوبغا الدودار المقر الأشرفي السيفي ) حكم فترة ( 741-742 هـ /1340-1341 م ) ،(الباشا، 1966، ص532) ، ( لوح 6 ) ، وزينت كذلك صينية نحاسية قليلة العمق ذو اطار بحافة مسطحة زخرفت بأشرطة من الزخارف المحفورة حفرا خفيفا 
ضم القسم المركزي رسوم مروحية الثكل نفذت على هيئة زهرة ثمانية البتلات يتوسطها رنك الدواة محاطة بزخارف حلزونية مورقة احاطتها جامات بيضوية تتعاقب معها اشرطة قصيرة بخط النسخ لعبارات دعائية باسم احد القضاة (لوح 7، 8 ) ، ومن الجدير بالإشارة ان الرنوك تأتي فيما سبق مفردة ولكن هناك العديد منها تأتي متضمنة رنكا اخر (Mayer,p 90) في كتابة ، شكل رقم (3 ) وقد يركب اثنان منها كما في رنك الدواة يشاركه رنك البقجة الذي سيستم ذكره لاحقا شكل رقم (4 ) . رنك البقجة:

يطلق هذا الرنك على وظيفة الجمدار وتعني الكلمة المكونة من مقطعين الاول (جم ) وتعني الثوب و (دار) هو ممسك الثوب الذي يختص بلباس السطان ويشترك بحراسته ، او ما يطلق عليه موظف الالبسة (العش، 1960، ص176) ، وتتقش اما على هيئة مربع ذو اركان مرتفعة أو شكل معيني يرمز الى قطعة نسيج تطوى اطرافها تجاه الوسط وكان يوضع فيها الملابس المعدة للاستعمال ويرسم عادة دائرة صغيرة فوق البقجة وهي اما ترسم بشكل مفرد أو مشتركة مع رموز اخرى (احمد، 1974، ص71)( انظر شكل 5 )، ومن اقدم الامثلة على التحف هي مبخرة كروية الثكل مصنوعة من النحاس المكفت بالفضة محفوظة حاليا بالمتحف البريطاني وتتسب الى الامير بدر الدين بيسري والمتوفى ( 697 هـ / 1298 م ) (عبدالرزاق، 1974، ص(93) (، لوح (9) رنك عصا البولو:

يدل هذا الرنك على عصا البولو وهو يثير الى وظيفة الجوكندار، وهي كلمة فارسية تتألف من مقطعين (جوكان ) بمعنى عصا. و (دار) تدل على حاملها او ماسكها، فتعد هذه الرياضة من اوسع الالعاب انتشارا في البلاط الخلافي، إذ اهتم بها المماليك والسلاطين (داود، 2010، ص235) وفي بعض الاحيان نجد هذا الرنك لعصا مزدوجة التي يشير الى الثخوص الذين يشرفون على تعليم لعبتها لكبراء الدولة في البلاط المملوكي (فارس، 1976، ص236)، وتم اضافة هذا الرنك متوسطا علبة معدنية داخل اطار دائري فيما ضمت العديد من الزخارف النباتية والزهور والوريدات ورسوم طيور حورت عن الطبيعية فضلا عن كتابة بخط النسخ دونت فيها الألقاب المملوكية (زكي، الاطلس، شكل 525) ، لوح (10) 
النسر :طائر من الجوارح قوي حاد البصر من الفصيلة النسرية رتبة الصقريات وهو اكبر الجوارح حجما وله منقار معقوف مدبب مزودة بقواطع حادة ، استخدمه السومريين والرومان والبيزنطيين وغيرهم أتخذ من العقاب ذو الرأسيين رمزا له. (الجاويش، (9004) 2004

اتخذت الطيور كرمز واشارات منذ زمن بعيد لاسيما في الشرق ، واحدى الزخارف والموضوعات الرئيسية التي أزدانت بها

التحف المعدنية بأنواعها فكان من المواضيع المهمة التي يعد الصيد واحد منها والصيد بالطيور الجارحة استخدمت بثكل كبير ونقلها لنا الفنان المسلم وحولها بثكل زخارف على المعادن ، ويعتبر النسر من اكثر الرموز ورودا على الأثار العربية والتحف المنسوبة الى العصر المملوكي وقد رسم برأس واحدة ملتفته الى اليمين او الى اليسار او برأسيين متدابربين وبعض الاحيان بجناح واحد أو جناحيين وتظهر المخالب ممسكة بنهاية الجناحيين ومن أقدم من اتخذ هذا الرمز رنكا السلطان الايوبي صلاح الدين ( 567-589 هـ / 1174-1193م ) حيث لانزال نراه يعلو اسوار القلعة التي بناها (زكي، 1979، ص12) ، واستخدم رنك النسر السلطان موسى بن علي بن قلاوون (678- 716 هـ/ 1317/1275م)، كما ويمثل النسر ذوو الراسين رنك الملك الارتقي الصالح محمود صاحب كيفا( 638-643هـ /1240-1249م )، اتخذ هذا ارنك للعديد من المماليك والامراء والسلطان منهم بهادر الحموي (693هـ / 1293 م ) وجمال الديم اقوش (736هـ / 1335 م ) وسيف الدين طقز (746 هـ / 1345م ) العش : الفخار غير المطلي (زكي،1979، ص179). ومن التحف المميزة التي نثاهدها مبخرة مصنوعة من النحاس المكفت بالفضة وهي محفوظة في المتحف البريطاني في لندن توسط المركز رنك لنسر ذو راسيين داخل اطر دائرية كررها بشكل منسق على كامل البدن ويلتف حولها زخارف نباتية لأغصان التوائية (الاربيسك ) فيما ضمت الاطر الاخرى نصوص كتابية دعائية للأمير المملوكي (وارد، 1998، ص124) لوح (11) . 
من الرنوك المهمة التي اشتملت عليها التحف المعدنية والتي دونت بها اسماء السلاطين والملوك والولاة مصحوبة ببعض العبارات الدعائية وسجلت اغلب هذه الرنوك بخطي الثلث والنسخ (مايسة، 1982، ص30)، حيث عرفت هذه النوعية من هذه الرنوك في المصطلح المملوكي باسم الدروع او الخراطيش التي قسمت الى عدة اقسام سواء كانت افقية او عمودية تتضمن الكتابات في القسم الاول اسم السلطان وفي الوسط عبارات التعظيم لله واسفله عبارات دعائية . ومن الرنوك الكتابية قاعدة شعدان لحمل شموع الاضاءة الجزء الاوسط اكثر بروزاً عن باقي القاعدة والجزء الوسطي من القاعدة يزينه زخارف نباتية متشابكة ، ويعلو هذا الثريط زخارف مجدولة لوح (12) ، اما الثريط الاعلى فيحتوي على زخارف كتابية منفذه على ارضية نباتية يتخللها رنك كتابي مكرر للسلطان المملوكي قاتيباي وهو مقسم الى ثلاث اجزاء العلوي ضم عبارة "ابو النصر قاتيباي "والجزء الوسطي "عز لمولانا السلطان الملك الاشرف " والسفلي ضم عبارة " عز نصره " ، ومن الامثلة الاخرى فاس معدني زين في وسطه رنك كتابي بخط النسخ لنفس الامير السابق ( 902-873 هـ /1468-1496م) (حسن، 1965، شكل 536) لوح (13) -

ومن الجدير بالملاحظة هناك مدرسة موصلية مشهورة جدا لابد ان تأتي على ذكرها كأهم مدرسة في صناعة التحف المعدنية ونظرا لذلك وصلت هذه التحف الى اقصى بقاع العالم واضحت احد اهم المعروضات الفنية لمتاحف الدول حيث حملت معها هذه التحف رسالة تبين براعة اهل الموصل في اتقان حرفتهم على الرغم من انتقالهم من الموصل الى بلاد الثام او مصر على حد سواء .

وأثرت الرنوك الكتابية بشكل واضح بما وصلت الينا من زخارف لتحف معدنية على سبيل المثال الطغراء العثمانية، الطغراء : لفظة اعجمية دخلت العربية واستعملت فيها كمصطلح على العلامة التي تكتب بقلم خاص في طرة الاوامر السلطانية ليكون في وجودها دليل على صحة نفوذ الاوامر ، لان الطغراء انما تعبر عن شخص السلطان وتقوم مقامة) (شعبان، 2013، ص347)، وهي شديدة الثبة بالرنوك الكتابية المملوكية بل احتمال كبير جاءت كمرحلة تطور عن الرنوك الكتابية لاسيما ان العثمانيين سيطروا على البلاد التي حكمها المماليك فمن الطبيعي ان يتأثروا بما انتجوه وما صنعوه ويحاولوا ان يقلدوه. 
من خلال اطلاعنا على العديد من المصادر والمراجع والكتب نستتتج مايلي :

1. الرنك ارتبط بشكل مباشر بالجهة السياسية التي تحكم البلد او الامصار الاسلامية حيث تتغير الرنوك او الرنك

الثخصي تبعا لتغيير السلطة الحاكمة او السياسية المتمثلة بالوالي •

عرضت الرنوك وبشكل واضح ما لعبته هذه الرموز وما تميز به العصر المملوكي على وجه الخصوص لا الحصر من

رقي وازدهار ورفاهية وثراء المجتمع واثره المباشر على حياة الامراء ورجال البلاط والمماليك من خلال تعدد الوظائف

وتتوعها بما يناسب وحياة الترف التي كانت سائدة في ذلك الوقت .

ومن الجدير بالذكر استخدمت المعادن لحمل الرموز ومن اهمها النحاس الذي يعد رخيص الثمن اذا ما قورن بغيره من

المواد حيث يسهل عمل انواع عديدة من المباخر والاواني والثمعدانات ونظرا لسهولة نقلها وانتشارها في البلاد نرى انه

جزء من فرض الهيمنة السياسية حتى أننا نجد مدى تأثر الناس برنك ملوكهم وامراءهم استخدامها على مقتتياتهم

وادواتهم المعدنية وهو خير دليل على وصول العديد من هذه الرنوك على التحف المعدنية وانتشارها بشكل واسع •

\section{الملاحق :}

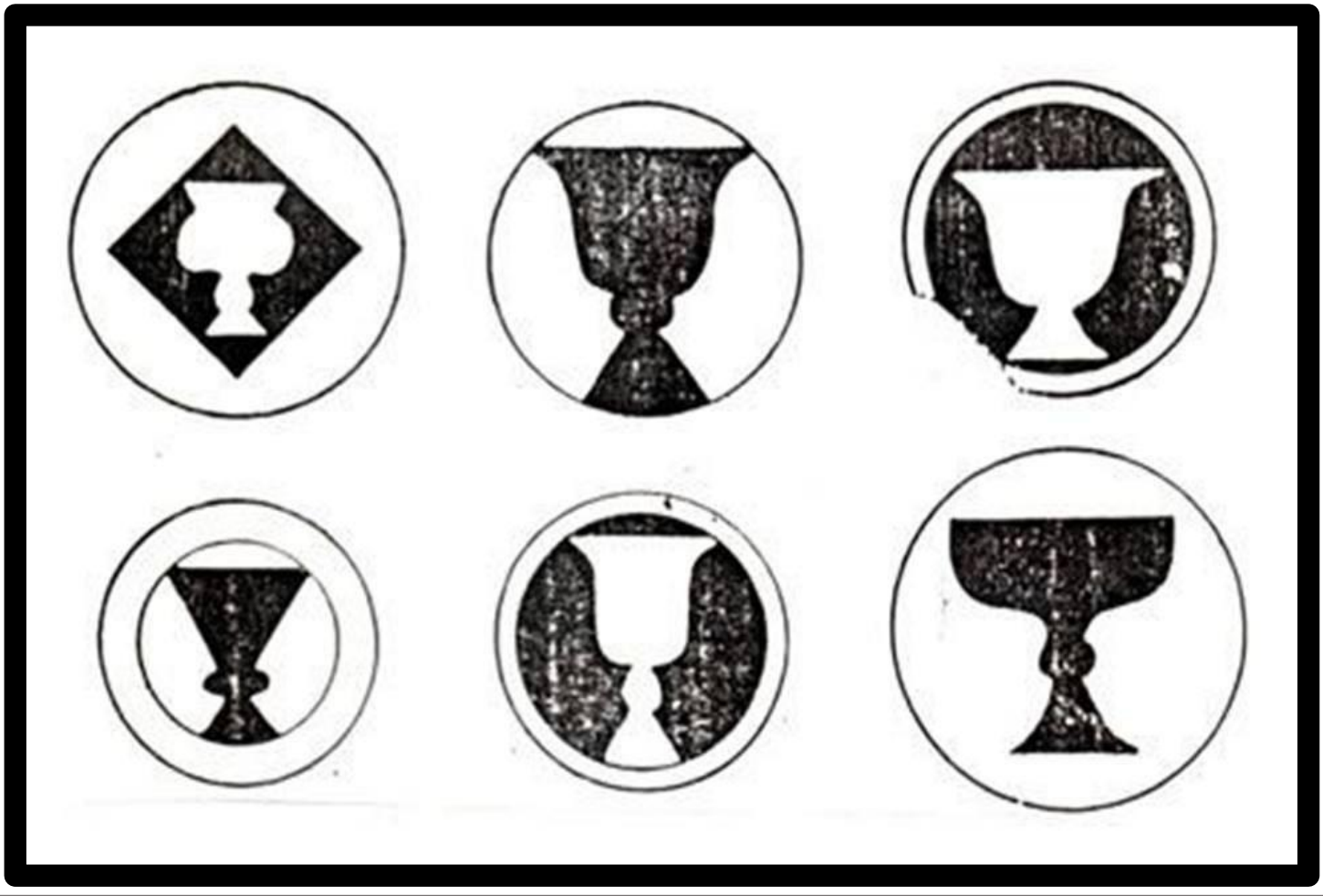




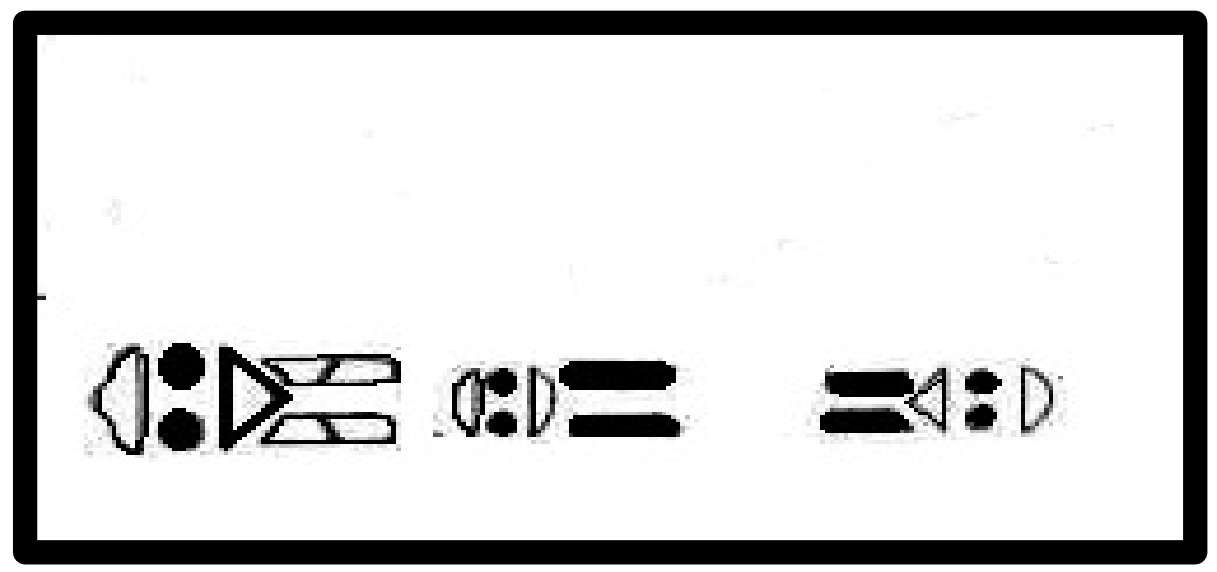

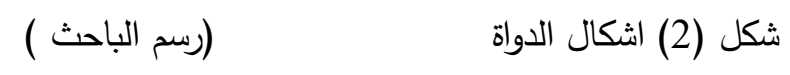

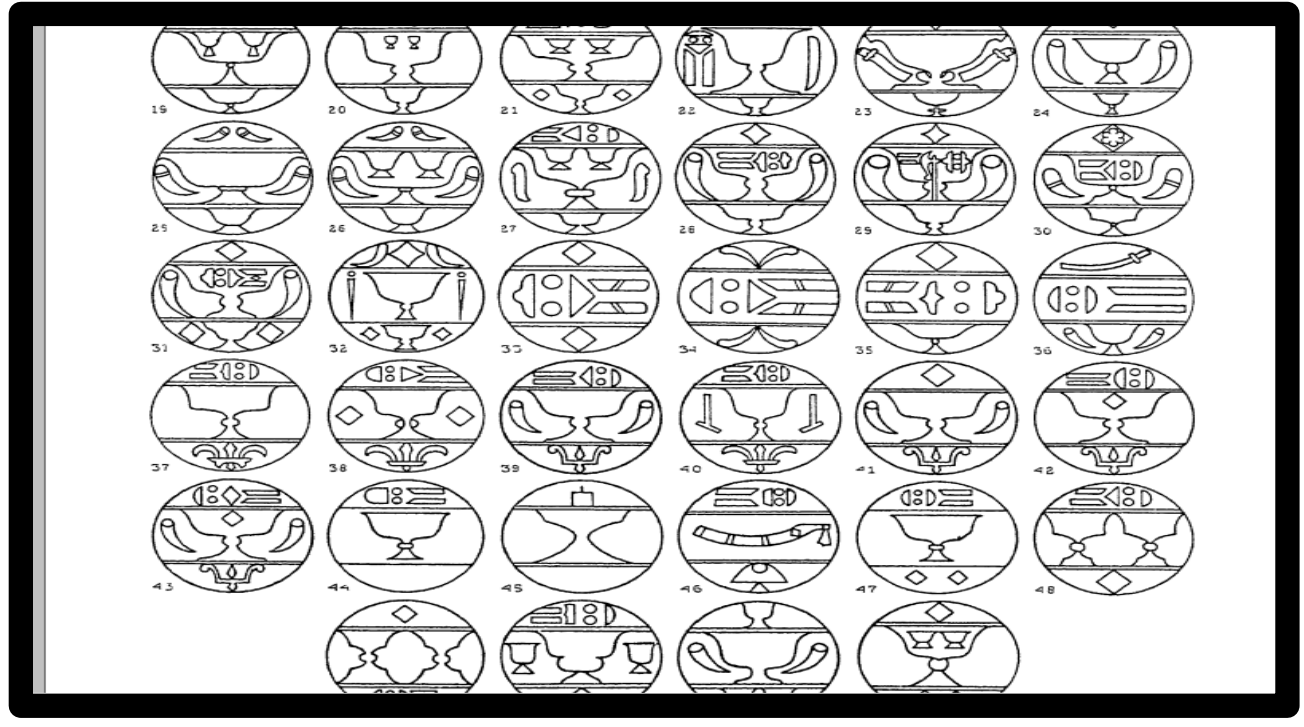




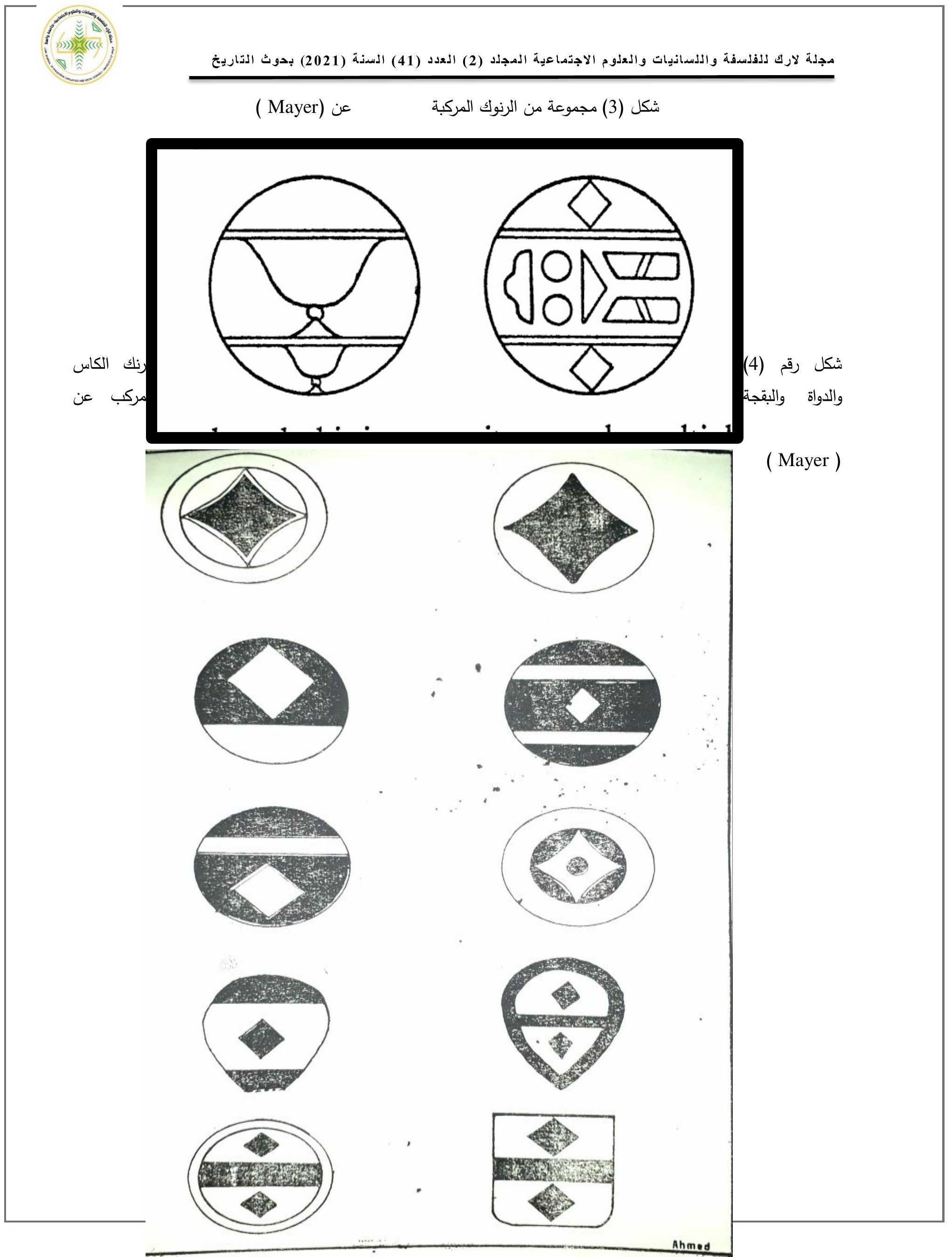




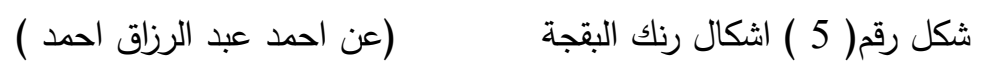

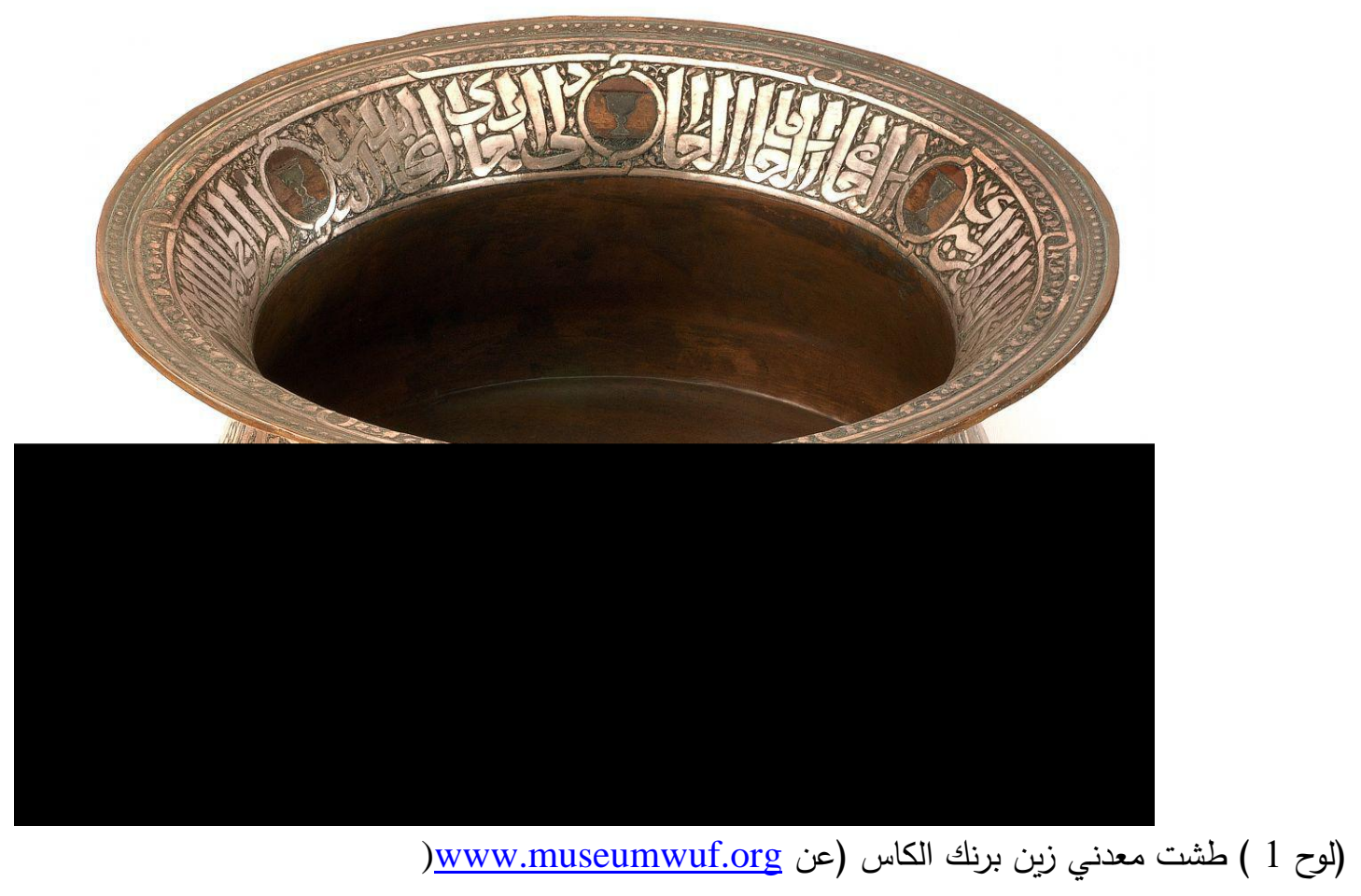




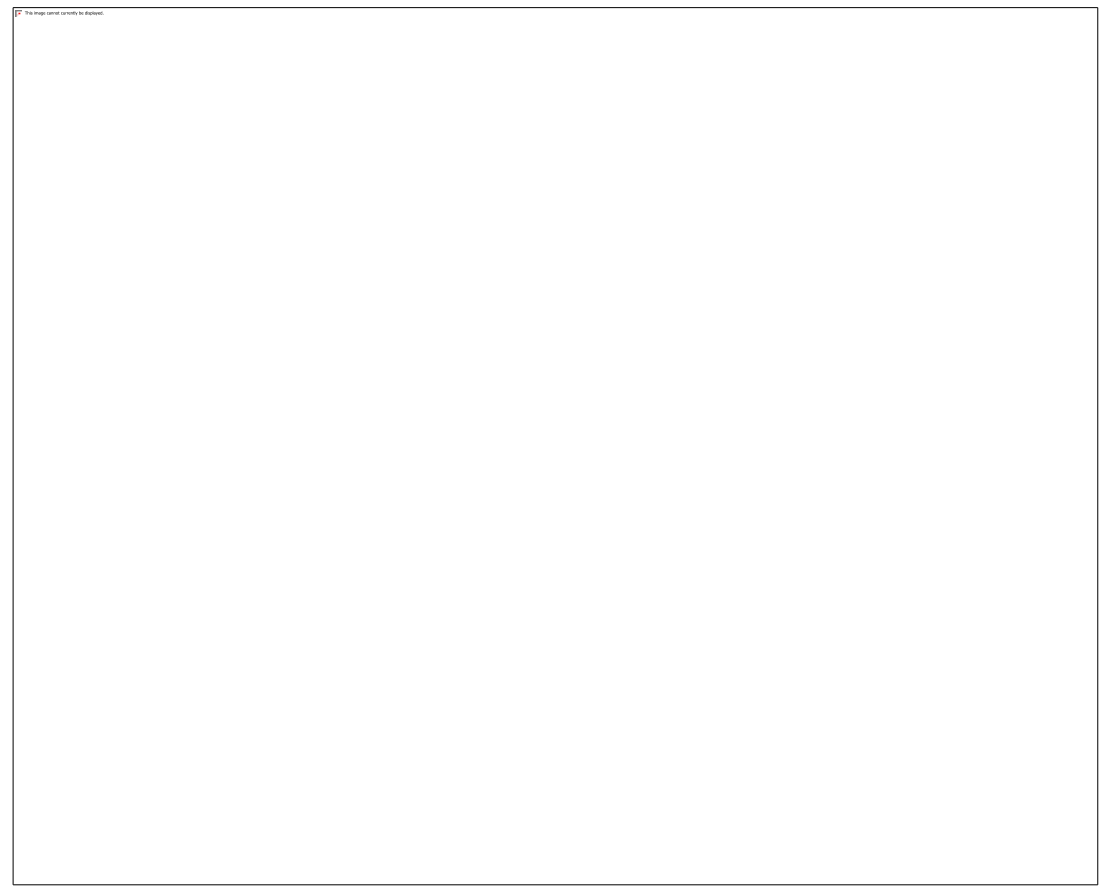

(لوح 2 ) علبة معدنية زينت برنك الكاس (عن: اطلس الفنون)

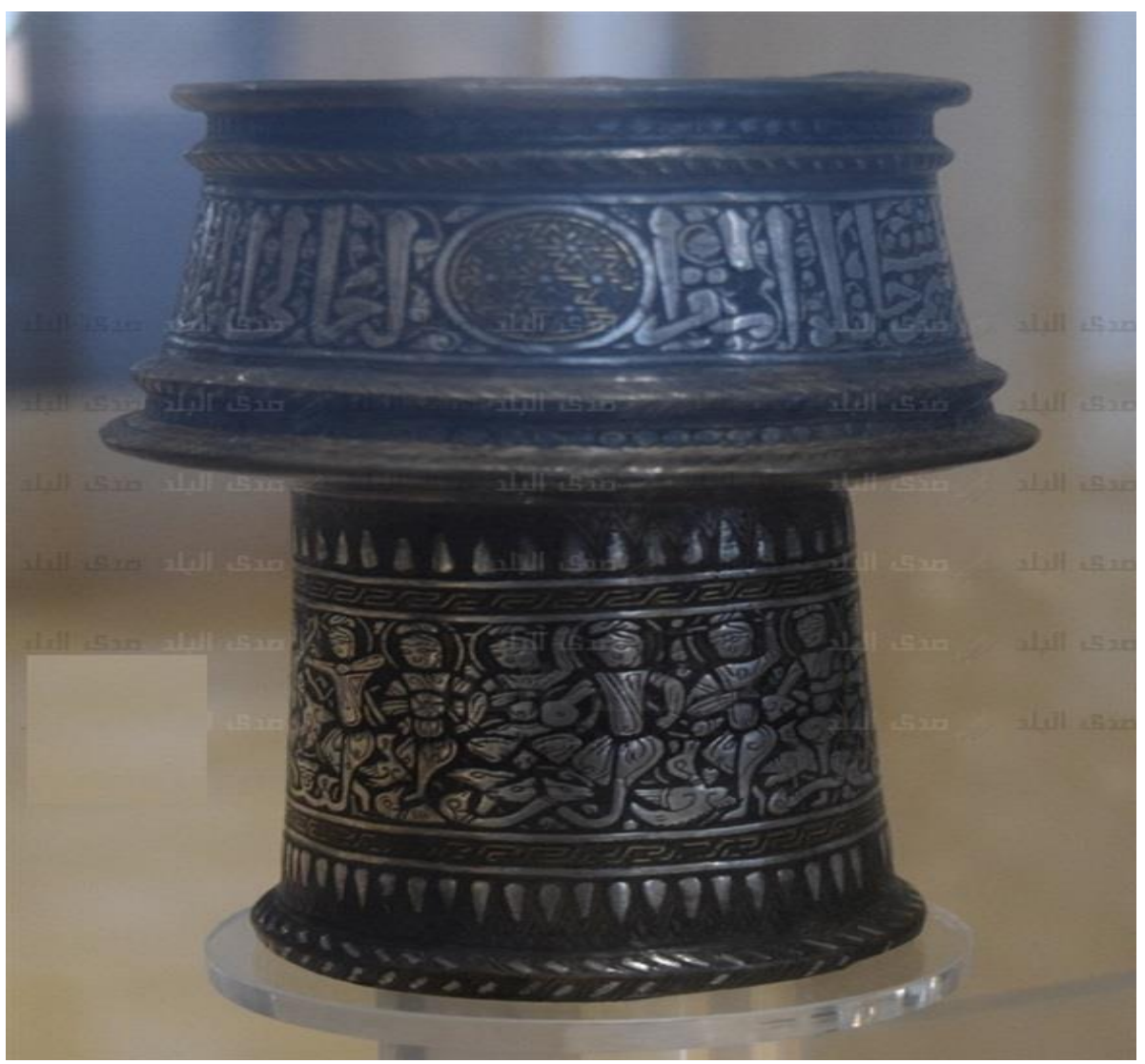


)www.museumwuf.org عن) لوح 3 شمعدان كتبغا

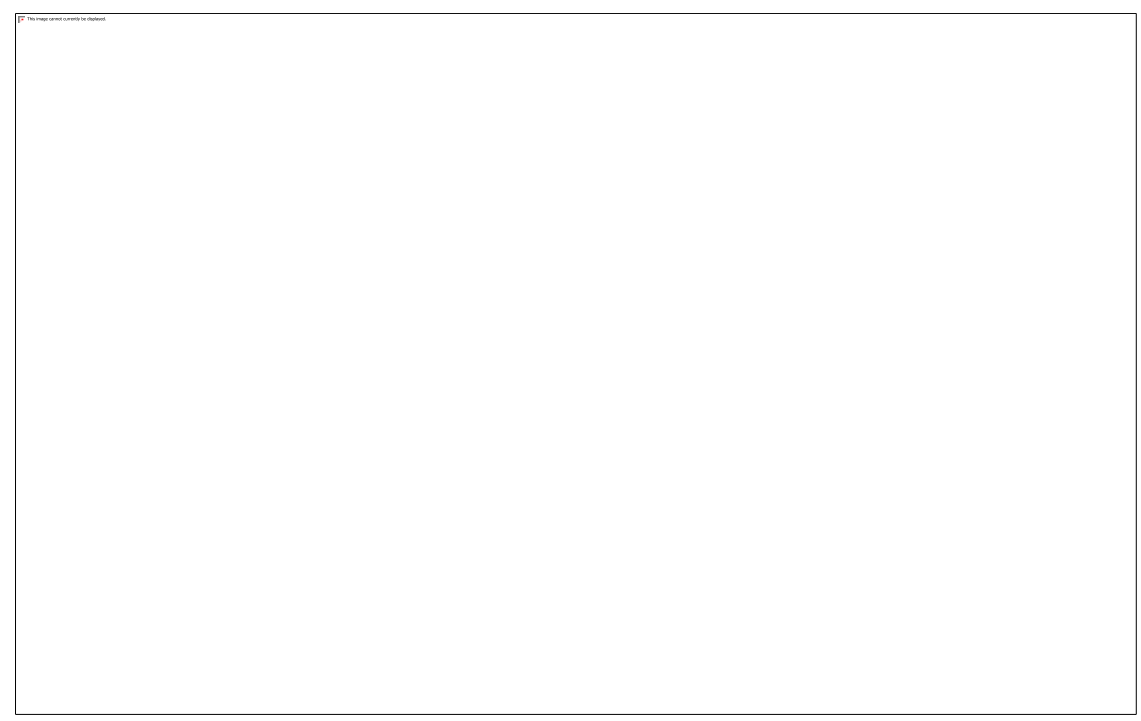

لوح( 4 ) صينية من النحاس تحمل رنك الكاس (دليل المتحف خان مرجان)
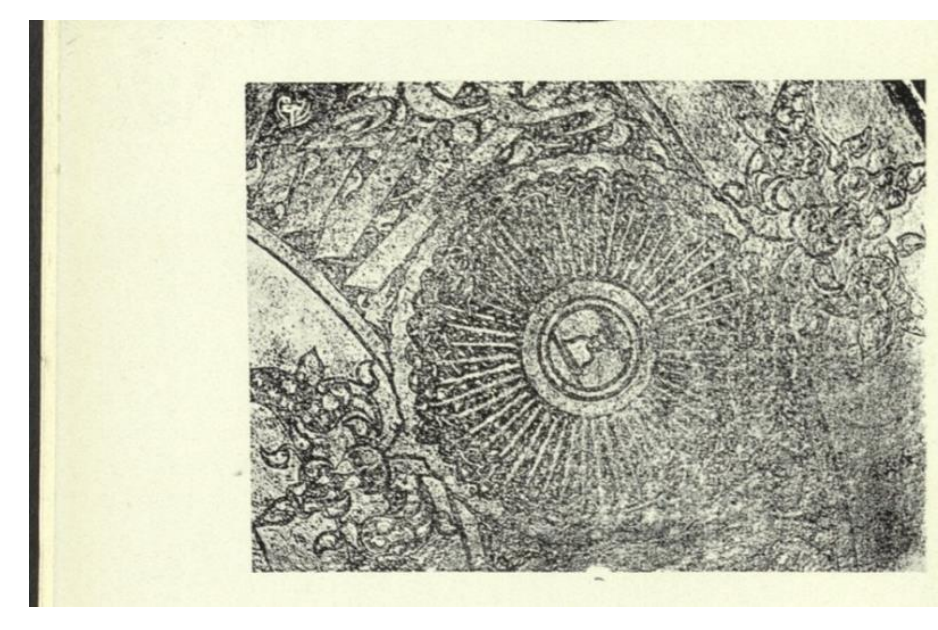

لوح( 4- 1 ) صينية معروضة في خان مرجان (دليل المتحف خان مرجان ) 


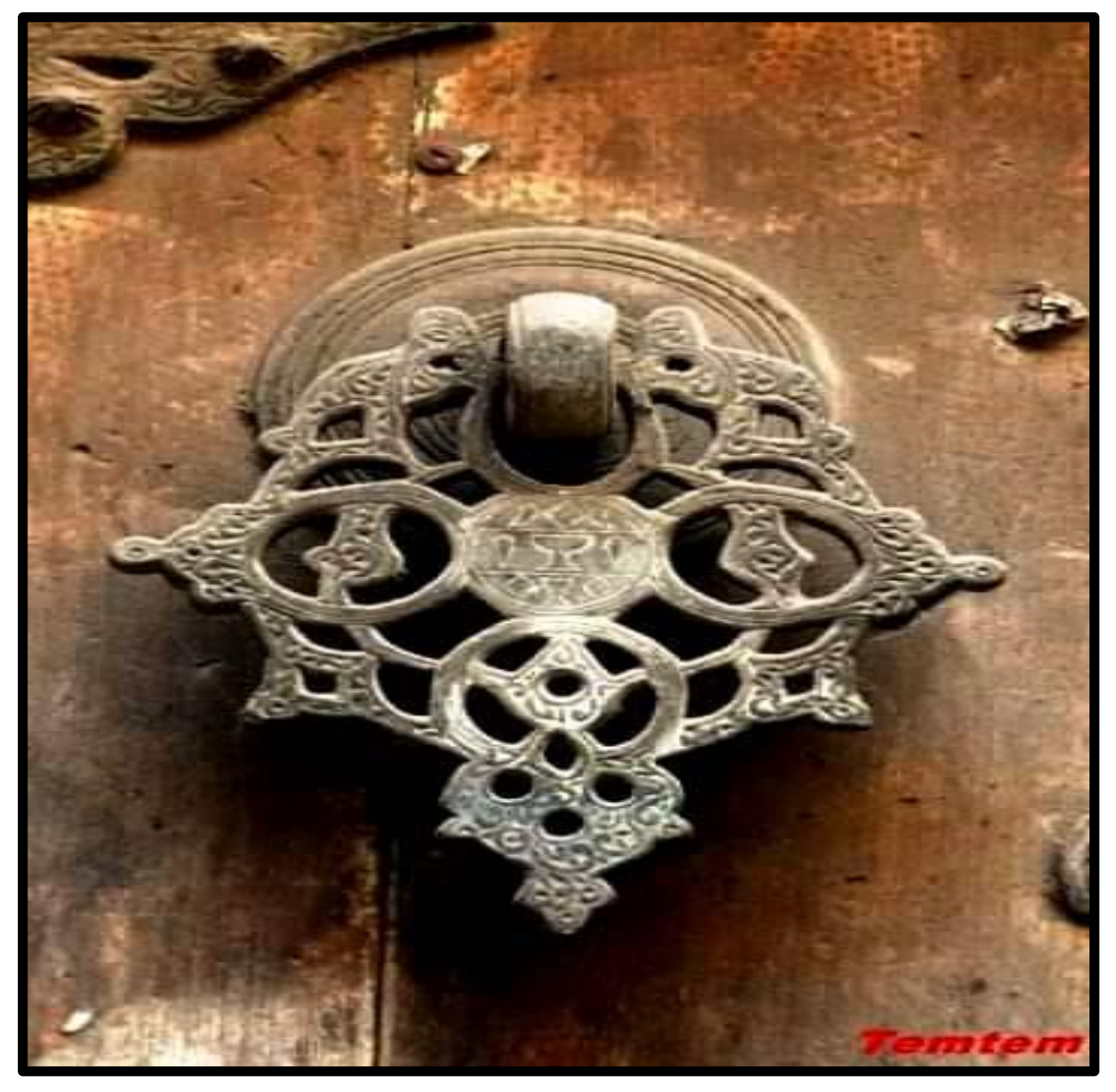

لوح (5) مطرقة باب مدرسة تمحل رنك الكاس (عن طنطاوي )

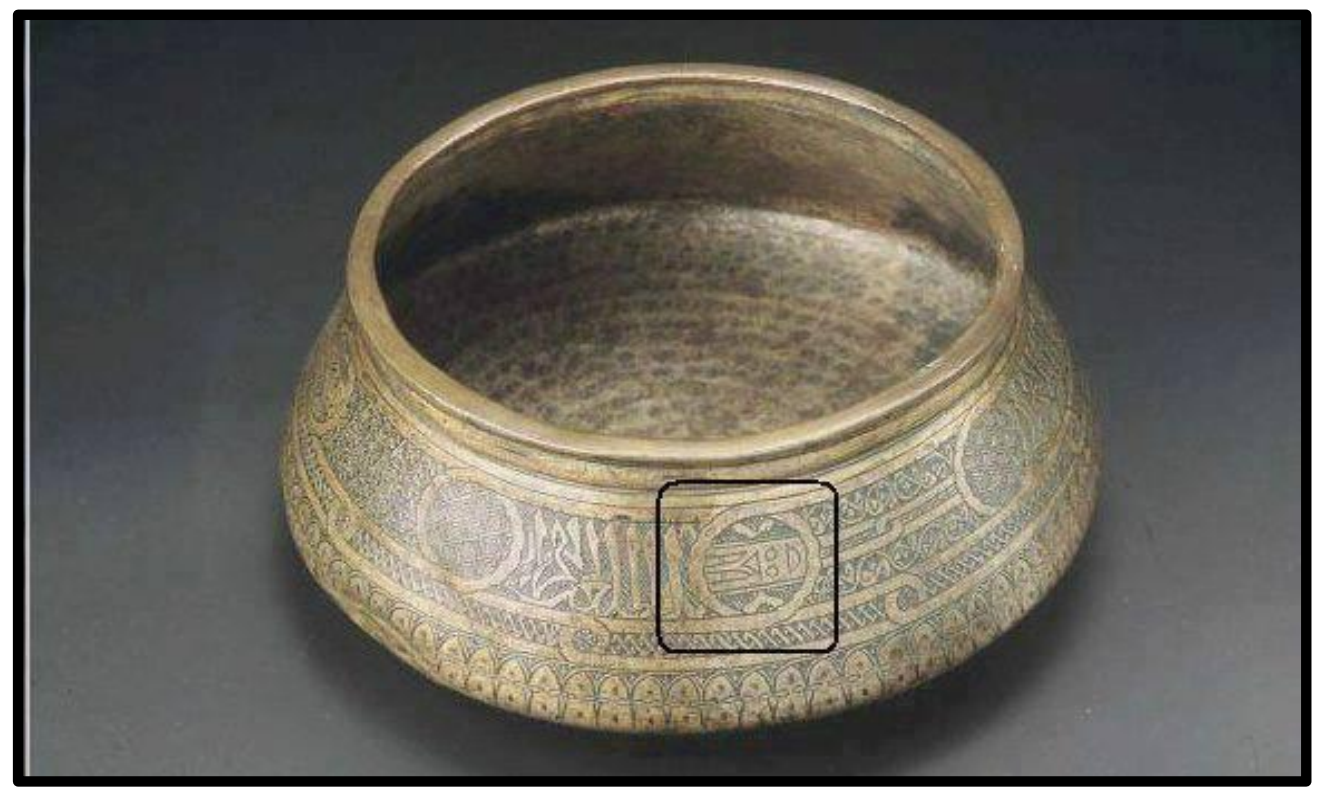




\section{لوح (6) طشت من النحاس زين رنك الدواة (عن www.museumwuf.org )}
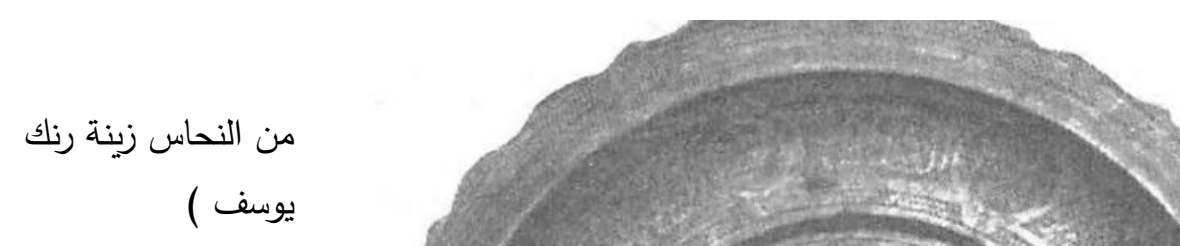

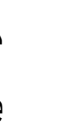
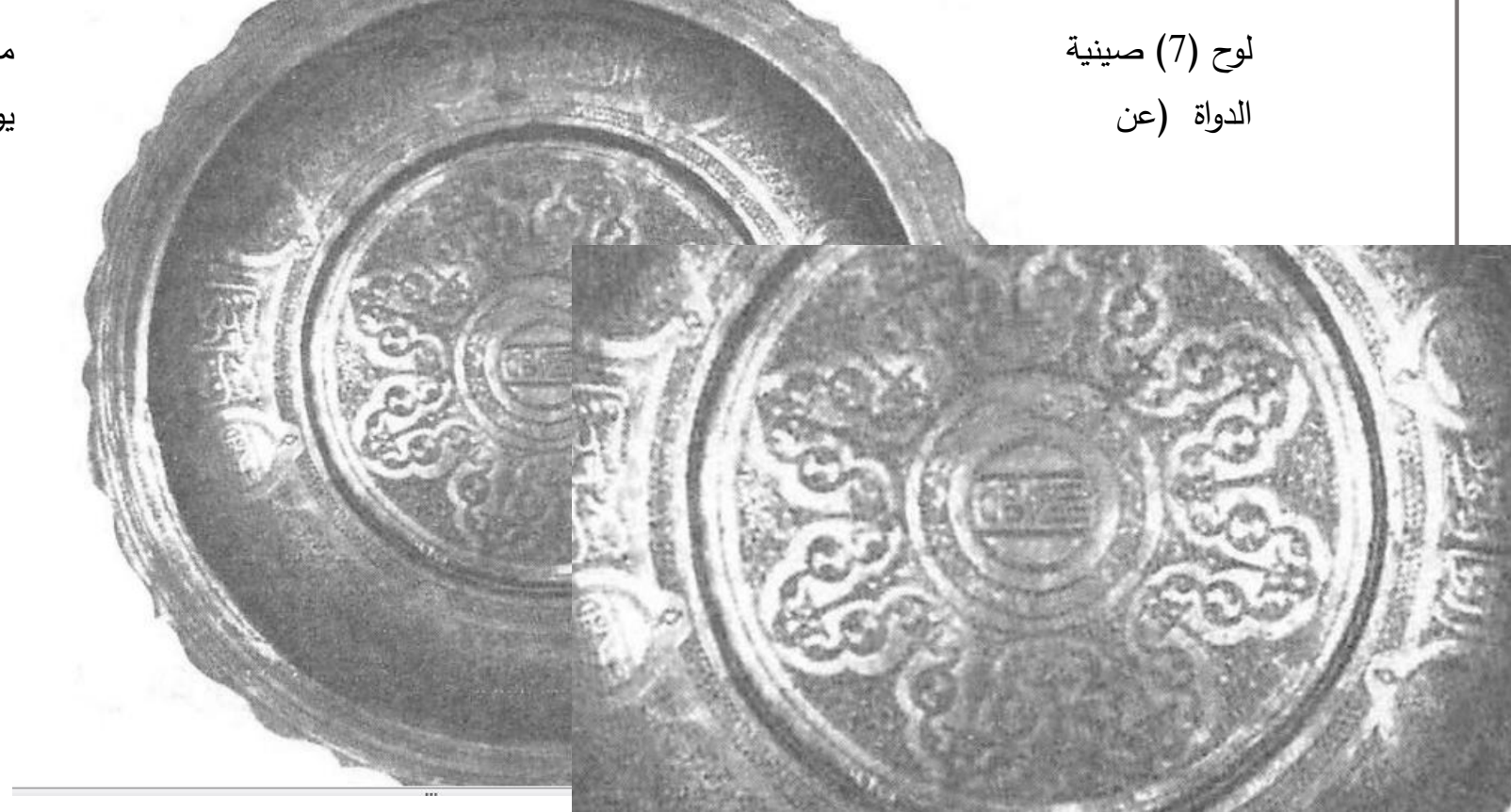

لوح ( 8 ) تفصيل الصينية لرنك الدواة (عن يوسف )

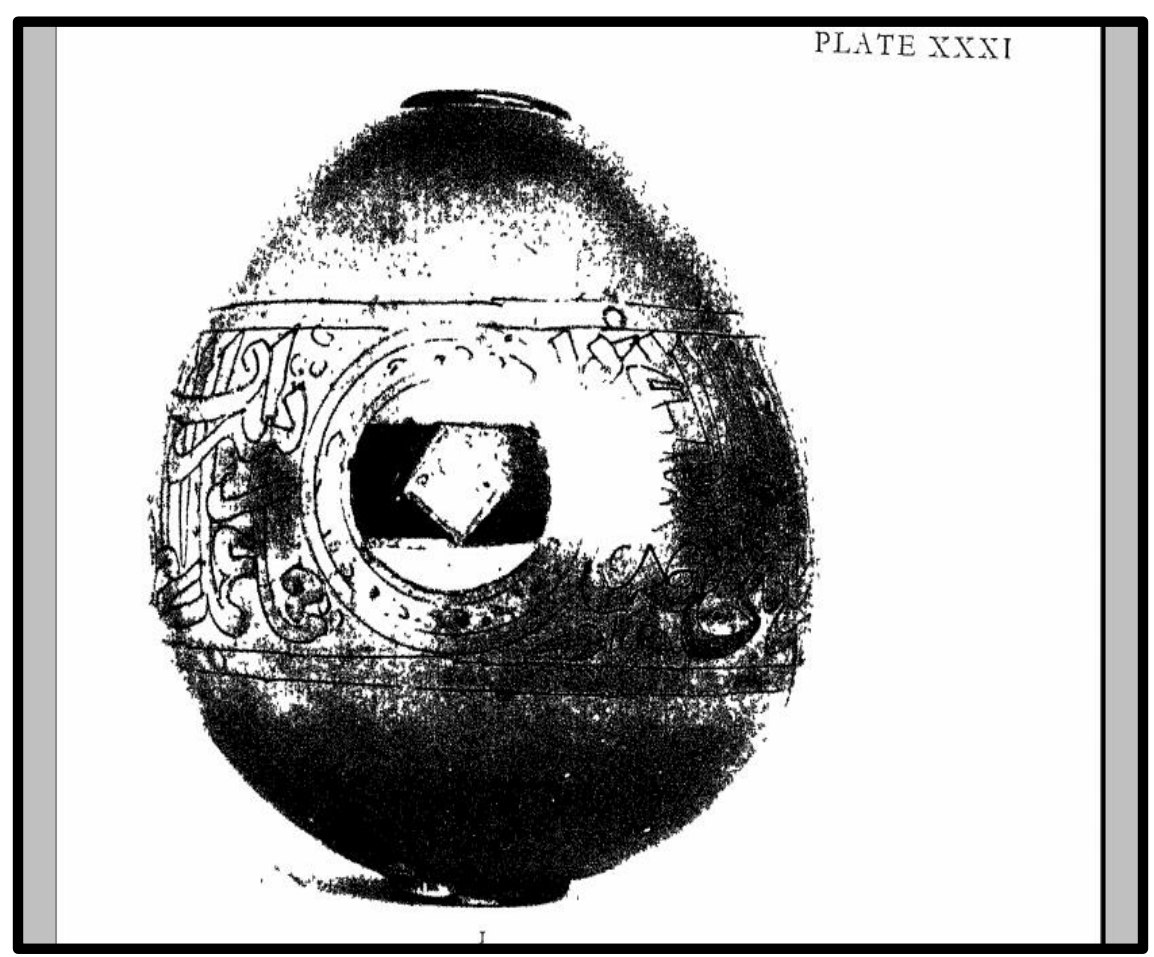


لوح (9) بيضة من النحاس تحتوي على رنك البقجة (عن Mayer)

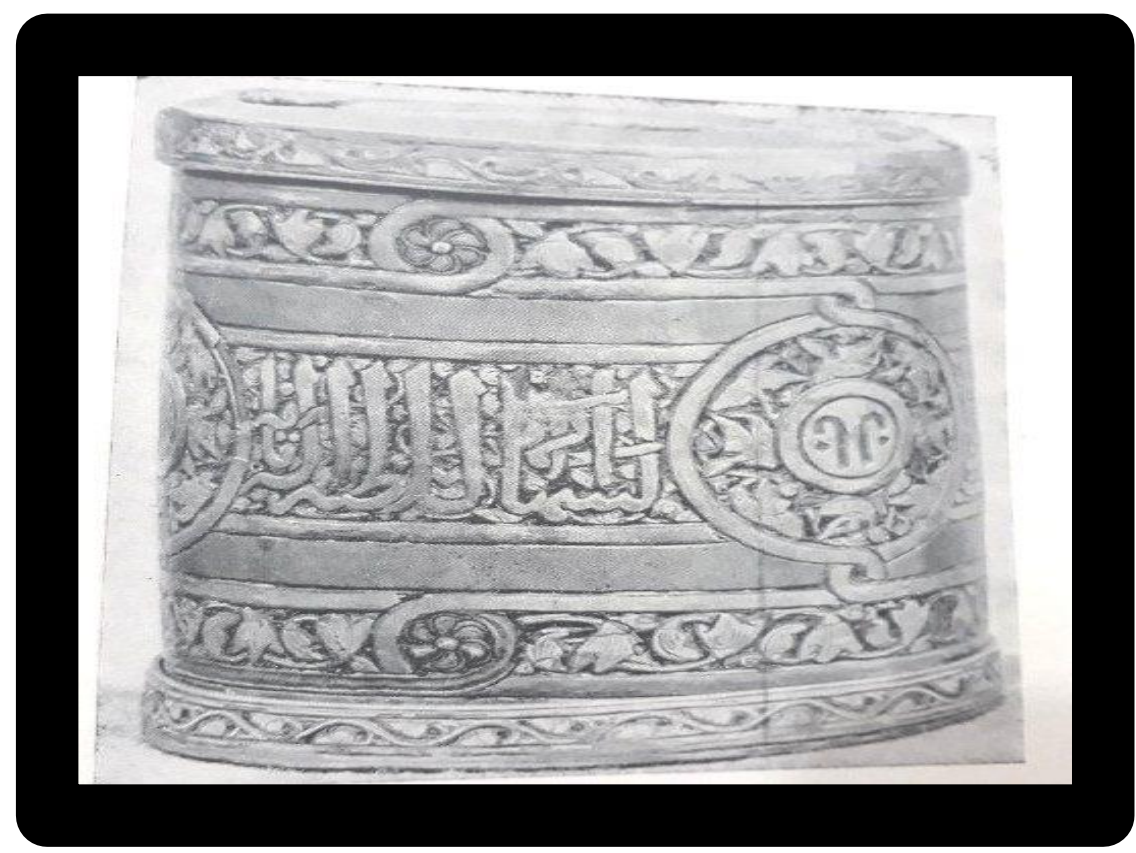

لوح 10 علبة معدنية تحتوي على رنك عصا البولو (عن زكي محمد )

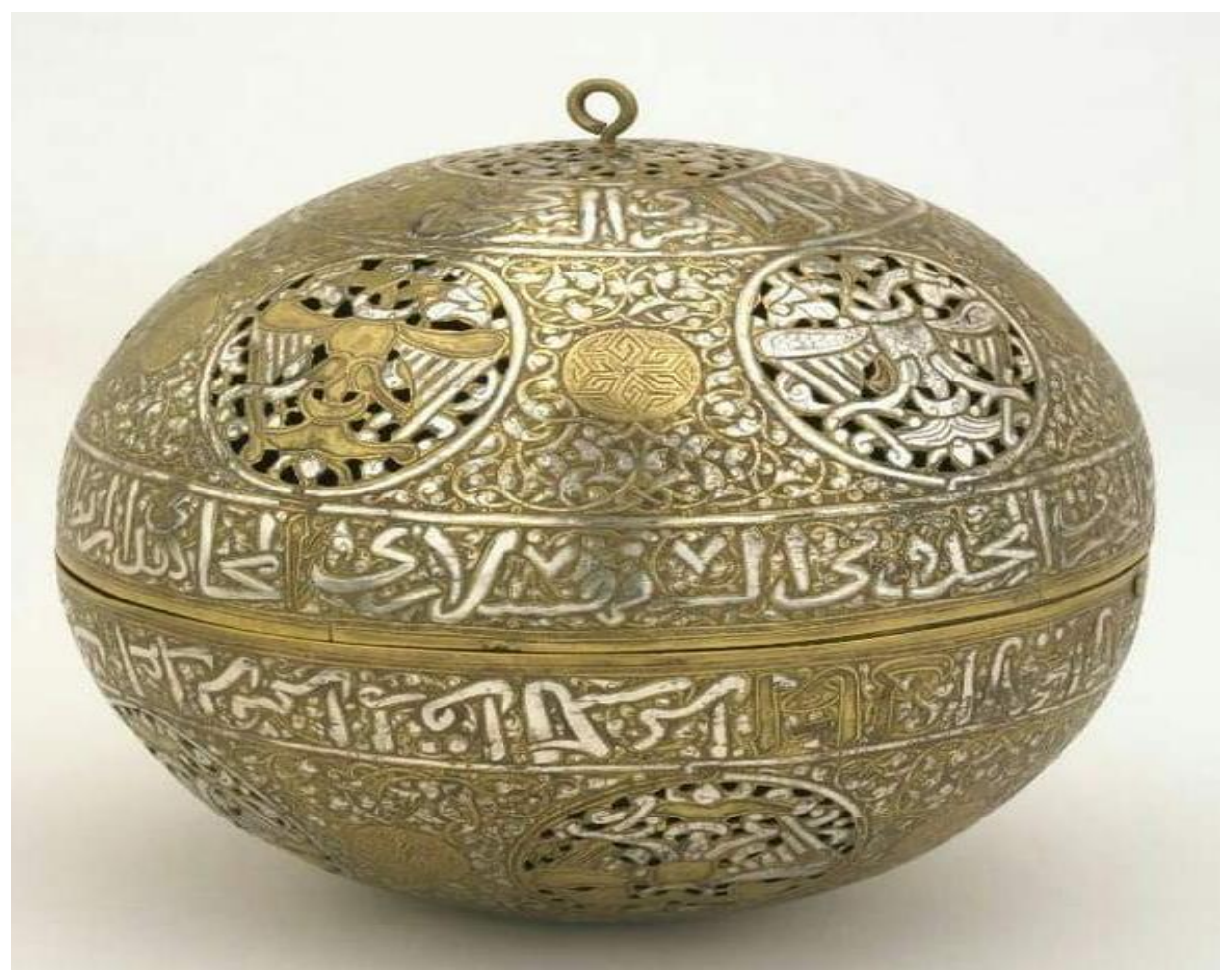


لوح (11) مبخرة من النحاس تحتوي على رنك النسر (عن وارد راشيل )

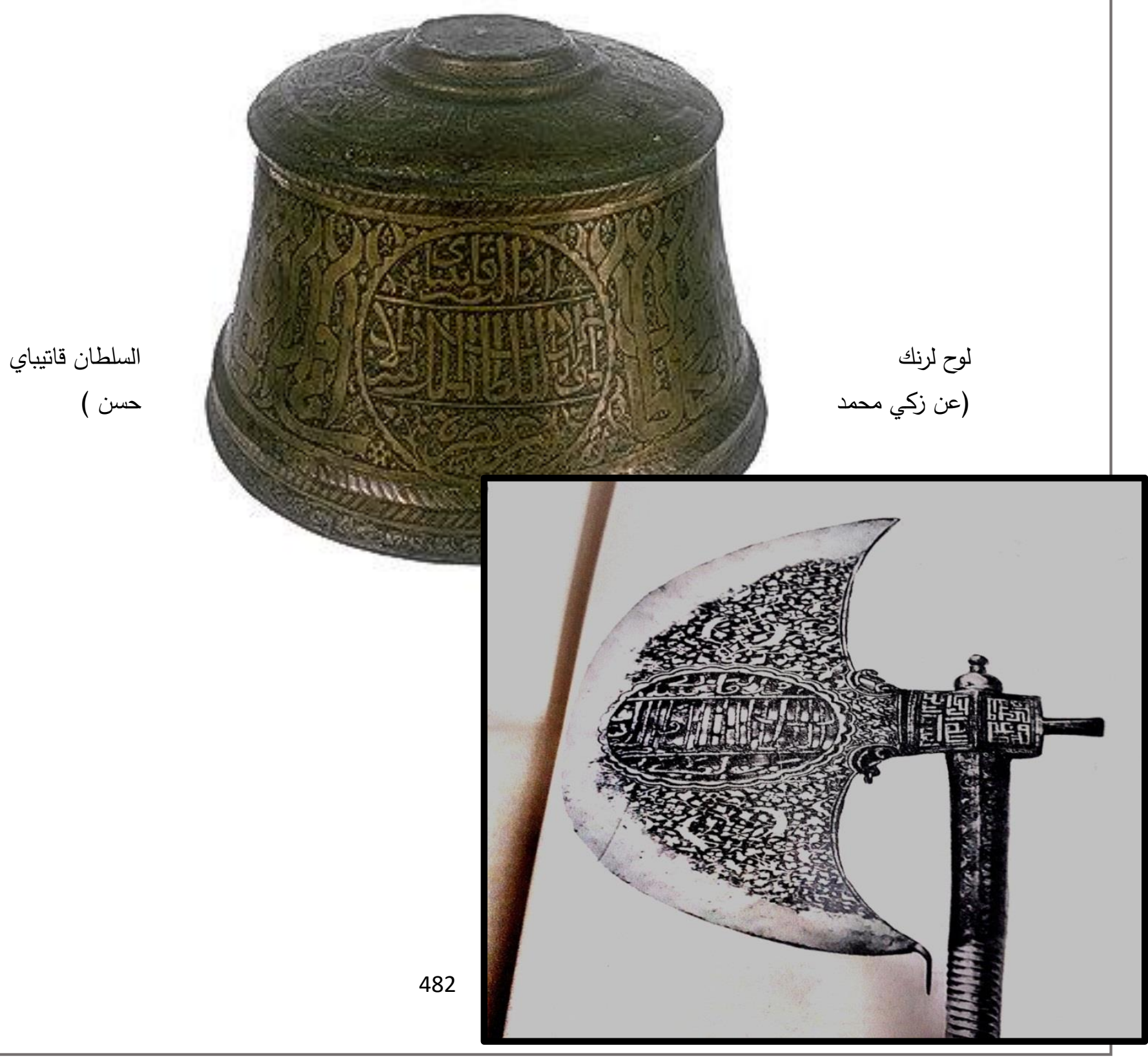




$$
\text { لوح (13) فاس كتب عليه رنك كتابي (عن زكي محمد ) }
$$

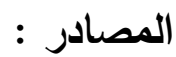

احمد ، احمد عبد الرزاق (1974) الرنوك على عصر سلاطين المماليك ، المجلة التاريخية المصرية ، مج 21 . الباشا ، حسن (1966) الفنون الاسلامية والوظائف على الاثار العربية ، ج 2. تودوروف ، تزفيتان (2012) نظريات الرمز ، ترجمة محمد الزكراوي ، المنظمة العربية للترجمة ، لبنان. الجادر ، وليد (1985) صناعة التعدين ، موسوعة حضارة العراق ، ج 2 ، بغداد. الجاويش ، محمد اسماعيل (2004) من عجائب الخلق في عالم الطيور ، الدار الذهبية. الجمعة ، احمد قاسم (1975) الاثار الرخامية خلال العهدين الاتابكي والايلخاني ، اطروحة دكتوراه ، جامعة القاهرة. حسن ، زكي محمد (1956) اطلس الفنون الزخرفية ، مطبعة جامعة القاهرة. حسن ، زكي محمد (1970) اطلس الفنون الزخرفية ، بغداد. حلاق، حسان وصباغ، عباس (1999) المعجم الجامع في المصطلحات الايوبية والمملوكية والعثمانية ذات الاصول العربية والفارسية ، بيروت. حميد ، عبد العزيز (1985) الفنون الزخرفية ( التحف المعدنية )، حضارة العراق ، جزء 9 ، بغداد. خضر ، محمود يوسف (2001) تاريخ الفنون الزخرفية ،دار السويدي ، الامارات. داود ، مايسة (2010 ) المعجم المصور للمصطلحات الاثرية (مختارات من موقع مصر الخالدة ) ، منشورات مركز التوثيق

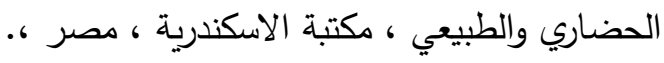
دليل متحف الاثار العربية في خان مرجان ،مطبعة الحكومة ، بغداد. دهمان ، محمد احمد (1990) معجم الالفاظ التاريخية في العصر المملوكي ، دار الفكر ، بيروت. زكي ، عبد الرحمن (1979) قلعة صلاح الدين وما حولها من الاثار ، القاهرة. زيغريد ، هونكه : شمس العرب تسطع على الغرب ، ص 42 . سيرنج ، فيليب (1992) الرموز في الفن والاديان والحياة ، ترجمة ، عبد الهادي عباس ، دمثق. 
شعبان ، محمد طلال (2013) الطغراوات العثمانية المذهبة في القرن 10 هـ / 16 م ، مجلة الخليج للتاريخ والاثار ، ع 8. الصفدي (1998) صلاح الدين خليل آيبك : اعيان العصر واعوان النصر ، حققه نبيل ابو عمشه واخرون ، ط 1 ، دمشق. صوى ،اولكر ارغين (2005) تطور فن المعادن منذ البداية حتى نهاية العصر السلجوقي ، ترجمة وتعليق ، الصفصافي احد القطوري ، القاهرة.

طنطاوي ، حسام عويس عبد الفتاح : مطارق الابواب في مصر في العصر المملوكي ، رسالة ماجستير غير منشورة ، كلية الآداب جامعة عين شمس •

طه ، فرج عبد القادر (دت) معجم علم النفس والتحليل النفسي ، دار النهضة بيروت . عبد الرزاق ، احمد (2001) الرنوك الاسلامية ، ط 1.

عبد العظيم ، محمد عبد المودود (2009)الكتابات والزخارف على النقود والتحف المعدنية في العصر المملوكي البحري ، ط1 ، ·لبنان العبيدي ، صلاح حسين : الفنون الزخرفية ، بغداد . عدره ، رشا (2013) الرنوك المملوكية في دمشق ، رسالة ماجستير غير منشورة ، جامعة دمشق ، كلية الاداب. العش ، ابو الفرج (1960) الفخار غير المطلي من العهود العربية الاسلامية في المتحف الوطني بدمشق ، الحوليات الاثرية السورية ، مج 10. علي ، جواد (1997) المفصل في تاريخ العرب قبل الاسلام ،ج 7 . العمري ، احمد عصمان (2012) الصنائع والمهن في نجد والحجاز في صدر الاسلام والعصر الاموي ، لبنان. غالب ، عبد الرحيم (1988) موسوعة العمارة الاسلامية ، بيروت. فارس ، محمد كامل (1976) الرنوك المملوكية في المملكة الحلبية ، مجلة عاديات حلب ، ج 2. الققشندي ، ابي العباس احمد (1915) صبح الاعشى ، دار الكتب الخديوية ، القاهرة ، ج 5 . كرستي ، آرثر : تراث الاسلام ، ج 2 ، مايسة ، داؤد (1982) الرنوك الاسلامية ، مجلة الدارة ، ع 3، السنة 70. مرزوق ، عبد العزيز (1965) الفن الاسلامي (تاريخه وخصائصه ) بغداد. مصطفى ، محمد (1944) الرنوك في عصر المماليك ، مجلة الرسالة ، س 9 ، ع 400 ، مصر . 
مصيلحي ، سعيد محمد (1983) ادوات واواني الطبخ المعدنية في العصر المملوكي ، اطروحة دكتوراه غير منشورة ، جامعة القاهرة ، كلية الاثار . ماكل

المعماري ، رعد سالم (2018) الصائغ وحرفته في العراق القديم في ضوء النصوص المسمارية ، مجلة اثار الرافدين ، م 3 ، ع

ابن منظور ، جمال الدين محمد بن مكرم : لسان العرب ، دار صادر ، بيروت ، ج 7 ، ص 287 . Www.musemwuf.org • من شبكة الانترنت

مهدي ، شفيق (2008) مماليك مصر وبلاد الثام (نقودهم - نقوشهم سمسكوكاتهم - القابهم - سلاطينهم ) 684-922 هـ/

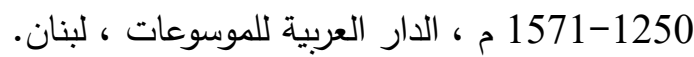
وارد ، راشيل (1998) الاعمال المعدنية ، ترجمة ليديا البريدي ، دار الكتاب العربي ، دمشق. يوسف ، علي نبيل (2010) موسوعة التحف المعدنية الاسلامية مصر منذ ما قبل الفتح الاسلامي حتى نهاية العصر

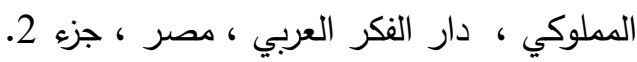

Brown, Katharine Reynolds : Guide to provincial Roman and Barbarian Metalwork and Jewelry in the Metropolitan Museum Art , New york , 1989 , p 2

Mayer, L.A: Saracenic Heraldry ,Oxfored, www.islamicart.museumwnt.org

\section{References}

Abdul Azim, Mohammed Abdel-Mooud (2009) Writings and decorations on coins and metal artifacts in the Mamluk maritime era, $1^{\text {st }}$ ed., Lebanon.

Abdul Razzaq, Ahmed (2001) Islamic Ringouk, $1^{\text {st }}$ ed.

Adra, Rasha (2013) Mamluk Runuk in Damascus, Unpublished Master's Thesis, Damascus University, Faculty of Literature.

Ahmed, Ahmed Abdul Razzaq (1974) The Ranuk on the Era of the Mamluk Sultans, The Egyptian Historical Journal, vol.21.

Al-Aish, Abu al-Faraj (1960) unpainted pottery from The Arab-Islamic Era at the National Museum in Damascus, Syrian Archaeological Yearbook, Vol. 10.

al-Basha, Hassan (1966) Islamic Arts and function on Arab Antiquities, part

Ali, Jawad (1997) detailed in the history of the Pre-Islamic Arabs, part 7.

Al-Jadir, Walid (1985) Mining Industry, Encyclopedia of The Civilization of Iraq, part 2, Baghdad. 
al-Jawish, Mohammed Ismail (2004) The wonders of creation in the world of birds, al-Dar al-Thabayia.

al-Jumaa, Ahmed Qasim (1975) marble relics during the Atabaki and Ilkhani periods, Doctoral dissertation , Cairo University.

Al-Mimary, Raad Salem (2018) Jeweler and his craft in ancient Iraq in the light of cuneiform texts, Magazine of The Effects of Rafidain, $M$

Al-mimary, Raad Salem (2018) jeweler and his craft in ancient Iraq in the light of cuneiform texts, magazine antiquities of Rafidain, M3, P 2.

Al-Obaidi, Salah Hussein: Decorative Arts, Baghdad.

Al-Omari, Ahmed Usman (2012) works and professions in Najd and Hijaz in the heart of Islam and the Umayyad era, Lebanon.

Al-Qalqandi, Abi Abbas Ahmed (1915) Sobh al-Ashi, Dar al-Kat

Al-Safadi (1998) Salaheddine Khalil Aibek: The Eyes of the Era and The Aid of Victory, achieved by Nabil Abu Amasha and others, $1^{\text {st }}$ ed., Damascus.

Brown, Katharine Reynolds : Guide to provincial Roman and Barbarian Metalwork and Jewelry in the Metropolitan Museum Art, New york, 1989 , p 2

Christie, Arthur: The Legacy of Islam, part 2,

Dahman, Mohammed Ahmed (1990) The Dictionary of Historical Words in the Mamluk Period, Dar alFikr, Beirut.

Daoud, Maysa (2010) Illustrated Dictionary of Archaeological Terms (Anthology of The Eternal Egypt Site), Publications of the Center for Cultural and Natural Documentation, Library of Alexandria, Egypt.

Fares , Mohammed Kamel (1976) Mamluk Ringouk in the Kingdom of Aleppo, Magazine Of The Habits of Aleppo, part 2.

From the Internet. www.musemwuf.org

Ghalib, Abdul Rahim (1988) Encyclopedia of Islamic Architecture, Beirut.

Guide to the Museum of Arab Antiquities in Khan Marjan, Government Press, Baghdad.

Hallak, Hassan and Sabbagh, Abbas (1999) The Universal Glossary in Ayyubid, Mamluk and Ottoman terms of Arab and Persian origins, Beirut.

Hamid, Abdul Aziz (1985) Decorative Arts (Metal Artifacts), Iraqi Civilization, Part 9, Baghdad.

Hassan, Zaki Mohammed (1956) Atlas of Decorative Arts, Cairo University Press.

Hassan, Zaki Mohammed (1970) Atlas of Decorative Arts, Baghdad. 
Ibn Mandhur, Jamal al-Din Mohammed bin Makram: Lisan al.arab, Dar Sader, Beirut, part.7.

Khader, Mahmoud Yusuf (2001) History of Decorative Arts, Dar al-Suwaidi, UAE.

Mahdi, Shafiq (2008) The Mamluks of Egypt and the Levant (their money, inscriptions, coins, titles, sultans) 684-922 Ah/1250-1571 A.D., Arab House of Encyclopedias, Lebanon.

Marzouk, Abdul Aziz (1965) Islamic Art (its history and characteristics) Baghdad.

Masilehi, Said Mohammed (1983) Metal cooking tools and pots in the Mamluk period, unpublished Doctoral thesis, Cairo University, Faculty of Antiquities.

Mayer, L.A: Saracenic Heraldry ,Oxfored,

Maysa, Da'ad (1982) Islamic Ring, Al-Dara magazine, part 3, Year 70.

Mustafa, Muhammad (1944) The Ringino in the Mamluk era, Al-Resala Magazine, Issue 9., Egypt.

Sawi, Ulker Ergin (2005) developed the art of metal from the beginning to the end of the Seljuk era, translation and commentary, Willow Ahmed Qatouri, Cairo.

Sering, Philip (1992) Symbols in art, religion and life, translation, Abdulhadi Abbas, Damascus.

Shaaban, Mohammed Talal (2013) And the Gilded Ottoman Tagrawat in the 10th century Ah / 16 AD, Gulf Journal of History and Antiquities, p. 8.

Taha, Faraj Abdel Kader (Dt) Dictionary of Psychology and Psychoanalysis, Renaissance House Beirut.

Tantawi, Hossam Aweys Abdel Fattah: Knocking doors in Egypt in the era. Unpublished Master's Thesis, Faculty of Arts, Ain Shams University.

Todorov, Tzvetan (2012) Theories of symbolism, Trans. Mohammed Al-Zakrawi, Arab Translation Organization, Lebanon.

Ward, Rachel (1998) Metal Works, Translation of Lydia Postal, Arab Book House, Damascus.

Www.islamicart.museumwnt.org.

Youssef, Ali Nabil (2010) Encyclopedia of Islamic Metal Artifacts Egypt from before the Islamic Conquest until the end of the era

Zaki, Abdul Rahman (1979) Salah al-Din Castle and its surrounding antiquities, Cairo.

Zigrid, Hunke: The Sun of the Arabs shines on the West, p. 42 